\title{
Medico-legal autopsy in postoperative hemodynamic collapse following coronary artery bypass surgery
}

\author{
Janne P. Karhunen • Pekka J. Karhunen • \\ Peter M. Raivio $\cdot$ Eero I. T. Sihvo • \\ Tiina L. S. Vainikka $\cdot$ Ulla-Stina Salminen
}

Accepted: 19 August 2010/Published online: 7 September 2010

(C) The Author(s) 2010. This article is published with open access at Springerlink.com

\begin{abstract}
Sudden unexpected postoperative hemodynamic collapse with a high mortality develops in $1-3 \%$ of patients undergoing coronary artery bypass surgery $(\mathrm{CABG})$. The contribution of surgical graft complications to this serious condition is poorly known and their demonstration at autopsy is a challenging task. Isolated CABG was performed in 8,807 patients during $1988-1999$. Of the patients, $76(0.9 \%)$ developed sudden postoperative hemodynamic collapse resulting in subsequent emergency reopening of the median sternotomy and open cardiac massage. Further emergency reoperation could be performed in $62(82 \%)$ whereas 14 patients died prior to reoperation and a further $21 \mathrm{did}$ not survive the reoperation or died a few days later. All 35 (46\%) patients who did not survive were subjected to medico-legal autopsy combined with postmortem cast angiography. By combining clinical data with autopsy and angiography data, various types of graft complications were observed in 27 (36\%, 1.3 per patient) of the 76 patients with hemodynamic collapse. There were no significant differences in the frequency (33 vs. $40 \%$ ) or number of complicated grafts per
\end{abstract}

\footnotetext{
J. P. Karhunen

Department of Orthopaedics and Traumatology,

Jorvi Hospital, Espoo, Finland
}

\section{P. J. Karhunen}

Department of Forensic Medicine, Tampere University Hospital, Tampere, Finland

P. M. Raivio · E. I. T. Sihvo · T. L. S. Vainikka

U.-S. Salminen

Department of Cardiothoracic Surgery, Helsinki University

Hospital, Helsinki, Finland

J. P. Karhunen $(\varangle)$

Jorvi Hospital, PL 800, 00029 HUS, Espoo, Finland

e-mail: Janne.Karhunen@hus.fi patient (1.2 vs. 1.4) between those who survived reoperation and who did not. Autopsy detected 25 major and minor findings not diagnosed clinically. Postmortem cast angiography visualized 2 graft twists not possible to detect by autopsy dissection only. Surgical graft complications were the most frequent single cause for sudden postoperative hemodynamic collapse in CABG patients leading to a fatal outcome in almost half of the cases. Postmortem angiography improved the accuracy of autopsy diagnostics of graft complications.

Keywords Malpractice $\cdot$ CABG $\cdot$ Postmortem angiography · Operative complication · Mortality · Autopsy

\section{Introduction}

Improvements in operative techniques and perioperative management in coronary artery bypass grafting $(\mathrm{CABG})$ have decreased mortality and morbidity depending on surgical procedures and the risk profile of the patient [1]. Recently, it was reported that $13(7 \%)$ of the patients in a large series comprising 114,233 CABG patients experienced major complications [2]. Because patients have more optimistic expectations about the benefits of coronary revascularization than the surgeon offering the procedure [3], unexpected complications may lead to litigations and malpractice claims, especially in cases with an unexpected fatal outcome. This may be one reason for the reluctance to revascularize the highest-risk cardiac patients, when operator-specific mortality statistics were made public [4], even though this has not been confirmed unambiguously [5]. Not surprisingly, it is hard to find reports on e.g. the contribution of surgical failures to the fatal outcome of the CABG patient [6,7].

In conventional $\mathrm{CABG}$ using cardiopulmonary bypass (CPB), the incidence of sudden unexpected postoperative 
hemodynamic collapse has been reported to range from 0.7 to $3 \%$ and to be associated with $30-50 \%$ mortality [8-11]. Postoperative myocardial ischemia, myocardial infarction and/or arrhythmias often precede the development of hemodynamic collapse $[8,9,12]$. Immediate resternotomy with open cardiac compression and appropriate surgical procedures including additional bypass grafting may result in patient survival $[8,11,13]$.

Only a few reports deal with detailed descriptions of surgical failures or complications or autopsy findings in cardiac surgery $[7,14,15]$. In one report, surgical complications were found to contribute to the death of $8(4.8 \%)$ patients in a series of 167 autopsies performed on cardiac surgery patients with a fatal outcome [7]. These complications included vein graft thrombosis, aortic dissection due to clamping, and retroperitoneal hemorrhage due to intra-aortic balloon pump and liver capsule tear during insertion of a chest drain. Early graft occlusion is also suggested as a frequent underlying cause of hemodynamic collapse $[6,8,9]$, but its prevalence is unknown.

The aim of this study was to study the incidence and causes of surgical failures and complications in the primary cardiac operation in patients with postoperative hemodynamic collapse resulting in emergency resternotomy and open cardiac massage. Clinical data were combined with careful autopsy dissection and postmortem cast angiographic visualization of the coronaries and grafts.

\section{Patients and methods}

A total of 8,807 patients underwent CABG without additional cardiac procedures in the primary operation between 1988 and 1999, with 162 (1.8\%) having a fatal outcome. Cases with sudden postoperative hemodynamic collapse and subsequent emergency reopening of the median sternotomy during postoperative intensive care unit treatment were singled out from the hospital reports and analyzed retrospectively. Patients with hemorrhage or pericardial tamponade were excluded from the study.

A total of $76(0.9 \%)$ patients fulfilled the criteria above and were included in the study. Preoperative patient description is given in Table 1. All patients had undergone conventional $\mathrm{CABG}$ with $\mathrm{CPB}$ and cardiac arrest with the exception of one patient who was operated on using CPB on beating heart. St. Thomas cold crystalloid cardioplegia and moderate hypothermia were used to protect the myocardium during surgery. Medico-legal autopsies in all cases with a fatal outcome were performed according to national law. In postoperative autopsies, a postmortem cast angiographic technique using solidifying silicone rubber with lead oxide as a contrast medium was routinely applied [6]. Autopsy reports were retrieved and re-analyzed. An
Table 1 Characteristics of the 76 patients who developed sudden hemodynamic collapse following coronary artery by-pass grafting (CABG)

\begin{tabular}{ll}
\hline & $N=76$ \\
\hline Gender (M/F) & $43 / 33$ \\
Age (years) & $58.2 \pm 1.0$ \\
Left ventricular ejction fraction (\%) & $55.3 \pm 1.8$ \\
Number of diseased vessels (1-3) & $2.26 \pm 0.9$ \\
Number of bypasses & $3.3 \pm 0.1$ \\
\hline
\end{tabular}

experienced cardiac surgeon in addition to the first author reanalyzed clinical and postmortem angiographies. A plain graft thrombosis as such was not considered as a surgical complication. A surgical graft complication was a narrow or occluded anastomosis, graft twisting or dissection of the site of anastomosis.

The study was accepted by the institutional ethics committee and was performed in accordance with the ethical standards in the 1964 Declaration of Helsinki.

\section{Statistics}

Data is presented as percentages of cases or as means \pm standard deviation. Fisher's exact test was used to compare the differences between patient groups. A $P$ value of less than 0.05 was considered statistically significant.

\section{Results}

The time of sudden hemodynamic collapse and subsequent emergency reopening of the median sternotomy with open cardiac compression was $8.1 \pm 1.6 \mathrm{~h}$ (range 0.17-91 h) after primary cardiac surgery. Of the 76 study patients, 62 $(81.6 \%)$ underwent further immediate reoperation whereas 14 (18.4\%) did not respond to the open cardiac massage and died prior to reoperation. Of those 62 who underwent an emergency reoperation 5 patients died on the operation table and a further 16 patients died later, $6.0 \pm 1.2$ days after the primary operation. Thus, of the 76 patients 41 (53.9\%) survived, whereas altogether $35(46.1 \%)$ patients suffered in-hospital death $5.1 \pm 0.8$ days after the primary cardiac procedure.

In the 62 emergency reoperations, $42(67.7 \%)$ patients received additional grafts and/or underwent graft repair.

\section{Graft complications}

Autopsy revealed myocardial findings in almost all those who suffered a fatal outcome (Table 2). In autopsy dissection findings and clinical operative findings, altogether 
Table 2 Autopsy findings in 35 patients with fatal outcome after hemodynamic collapse following $\mathrm{CABG}$

Of the 35 patients, 14 died immediately but 21 underwent further emergency cardiac operation

MI myocardial infarction
Immediate death

$14(40.0 \%)$

Death after emergency

cardiac procedure

$21(60.0 \%)$

Procedures in reoperation
No graft procedure
Number of additional grafts/graft repair
Autopsy findings
Perioperative MI
Old MI scar
Non-cardiac organ disease
Multiorgan failure

$8(38.1 \%)$

18

$\begin{array}{rrr}13(92.9 \%) & 17(81.0 \%) & \text { n.s. } \\ 13(92.9 \%) & 21(100 \%) & \text { n.s. } \\ 9(64.3 \%) & 16(76.2 \%) & \text { n.s. } \\ 3(21.4 \%) & 6(28.6 \%) & \text { n.s. }\end{array}$

35 graft complications were revealed in 27 (35.5\%) patients. Of these, 16 graft complications were found in 13 $(31.7 \%)$ of the 41 survivors, whereas slightly more-19 graft complications-were found in 14 (40.0\%) of the 35 patients who died $(P=0.34)$. Furthermore, a graft complication was revealed in all 5 who died on the operation table, and in 9 of the 16 patients, who died later after the emergency reoperation. In $7(20 \%)$ dead patients a graft thrombosis without underlying surgical failure was found. Postmortem cast angiography revealed 2 graft twists not observed in routine autopsy dissection (Table 3.). In one patient, postmortem angiographic finding of an occluded anastomosis turned out to be a narrowed anastomosis with minor thrombosis at autopsy dissection. In addition, of the $7(9.2 \%)$ patients with preoperative acute myocardial infarction, graft complications were found in 2 of the 4 patients with a fatal outcome.

In 3 patients postmortem angiography was not performed and in these cases the results are based on autopsy dissection only. In these autopsies, all grafts were considered technically intact, though in one patient all 3 venous grafts were thrombosed. In this patient one graft with occluded anastomoses had been replaced by a new graft in the emergency reoperation.

Table 3 Comparison of autopsy dissection findings with post-mortem angiographic findings in autopsies in a series of 35 patients with fatal outcome after hemodynamic collapse following CABG

\begin{tabular}{lclc}
\hline & Autopsy & Angiography & Difference \\
\hline Narrow native vessel & $13(40.6 \%)$ & $13(40.6 \%)$ & 0 \\
Graft thrombosis & $10(31.3 \%)$ & $11(34.4 \%)$ & +1 \\
Graft twisting & $0(0 \%)$ & $2(6.3 \%)$ & +2 \\
Narrowed anastomosis & $5(14.3 \%)$ & $4(12.5 \%)$ & -1 \\
Occluded anastomosis & $1(3.1 \%)$ & $2(6.3 \%)$ & +1 \\
Proximally occluded & $1(3.1 \%)$ & $1(3.1 \%)$ & 0 \\
$\quad$ anastomosis & $1(3.1 \%)$ & $1(3.1 \%)$ & 0 \\
Coronary artery dissection & $7(21.9 \%)$ & $6(18.8 \%)$ & -1 \\
No pathological findings & & &
\end{tabular}

Angiographies were not available for 3 cases
Among the patients who did not survive, clinical observation of a pulmonary complication prior to death was made in $3(8.6 \%)$. Autopsy confirmed pulmonary edema in $20(57.1 \%)$ cases. In $9(25.7 \%)$ patients neurological complications were detected prior to death, and autopsy revealed cerebral complications in 10 (28.6\%). Clinically $5(14.3 \%)$ patients were anuric, whereas in autopsies renal infarction was found in $2(5.7 \%)$ patients.

The underlying cause of death was considered cardiac in each case. The most common immediate cause of death turned out to be acute myocardial infarction in $29(82.9 \%)$ patients. Multiorgan failure developed in $9(25.7 \%)$ patients (Table 4).

\section{Discussion}

This study confirms that a hemodynamic collapse following $\mathrm{CABG}$ during the immediate postoperative course is a serious complication with a hospital mortality comprising almost half of the patients [8-11]. In our study one third of the patients and $40 \%$ of those who died had some technical graft complication, which seems to be the major underlying cause of the hemodynamic collapse. This figure was slightly lower than in our previous report with detailed autopsy examination, in which association of graft complications to death was $54.7 \%$ [6]. The minor discrepancy is explained by the fact that in our previous report all graft thromboses, even those with patent anastomoses and without twisting and kinking, were classified as graft complications, whereas in the present report we counted only technical failures causing thrombosis as graft complications. Death due to myocardial infarction was found in the majority of the patients and it seemed to associate frequently with intra-operative and/or autopsy findings of surgical graft failures.

In a previous study [7], the frequency of surgical failures was $4.8 \%$ which is a significantly lower figure compared to our results. This difference may be due to use of 
Table 4 Cause of in-hospital death in 35 non-survivors of those 76 with hemodynamic collapse and open cardiac massage after $\mathrm{CABG}$

$C A D$ coronary artery disease, $V F$ ventricular fibrillation

\begin{tabular}{llll}
\hline Cause of death & $\begin{array}{l}\text { Immediate } \\
\text { death } \\
N=14\end{array}$ & $\begin{array}{l}\text { Death after emergency } \\
\text { cardiac procedure } \\
N=21\end{array}$ & $P$ value \\
\hline Immediate cause & $13(92.8 \%)$ & $16(76.2 \%)$ & n.s. \\
$\quad$ Perioperative MI & $1(7.1 \%)$ & $1(4.8 \%)$ & n.s. \\
Acute cardiac insufficiency & $0(0 \%)$ & $1(4.8 \%)$ & n.s. \\
Acute graft thrombosis & $0(0 \%)$ & $1(4.8 \%)$ & n.s. \\
Coronary artery disease & $0(0 \%)$ & $1(4.8 \%)$ & n.s. \\
Cerebral infarction following period of VF & $0(0 \%)$ & $1(4.8 \%)$ & n.s. \\
Severe arrhythmia & & & \\
Contributing factor & $7(50.0 \%)$ & $13(61.9 \%)$ & n.s \\
Pulmonary edema & $1(7.1 \%)$ & $9(42.9 \%)$ & 0.02 \\
Cerebral infarction/edema & $2(14.3 \%)$ & $0(0 \%)$ & n.s. \\
Renal infarction/necrosis & $2(14.3 \%)$ & $1(4.8 \%)$ & n.s \\
Infection & $3(21.4 \%)$ & $6(28.6 \%)$ & n.s. \\
Multiorgan failure & &
\end{tabular}

postmortem cast angiography, which gives detailed data on the condition of the grafts and the tightness of the anastomoses [6]. It has also been used to detect main cerebral artery thromboses with a sensitivity of 92\% [16], and to visualize complications after abdominal surgery [17]. However, careful dissection of the coronary arteries and grafts can still not be replaced by postmortem angiography only to obtain detailed data on the complication site.

The study highlights the value of an autopsy in postoperative deaths following cardiac surgery. Suspected or possible surgical malpractice is one of the indications of a medico-legal autopsy in Finland, and that is why our postoperative autopsy rate is $100 \%$. There are some reports with autopsy rates as high as 84-88\% [7, 14]. However, discrepancies between clinical and autopsy studies are also reported in studies with lower $(24.5 \%)$ autopsy rates [15]. Autopsy reveals an unsuspected cause of death in $7-15 \%$ [7, 14, 15, 18], but it has also been reported to fail in providing an exact diagnosis in $14-25 \%$ of cases [14, 15], in contrast to our study where the cause of death was revealed in all cases.

Aside from perioperative myocardial infarction, a main contributing factor seemed to be pulmonary edema, which may develop rapidly as a consequence of cardiac failure or during cardiac resuscitation with rapid fluid filling of the patient, especially in those who died immediately. However, pulmonary edema and cerebral infarction or ischemic cerebral edema were more common among those who died later, after the emergency reoperation. As expected, multiorgan failure developed in those patients who died after the reoperation, and in those who died immediately due to hemodynamic collapse but had survived several days prior to collapse.
A medico-legal autopsy performed by an unbiased professional convinces the relatives of a neutral investigation of the operative death. In most cases the cause of death is ascertained [7, 14, 15, 18], as in the present study. In addition, the rights of the deceased, the relatives, and the surgeon are better protected, when an autopsy is performed. This might also result in decreased litigation. In this study there were no legal consequences, even in cases with operative complications resulting in death.

Our results suggest that technical graft complications are a frequent underlying cause of sudden postoperative hemodynamic collapse after $\mathrm{CABG}$ resulting in a fatal outcome in almost half of the patients. As well as categorical application of postoperative autopsies, our results also demonstrate that postmortem angiography improves the diagnostics of graft complications and is useful to combine with postoperative autopsy dissection.

\section{Key points}

1. Hemodynamic collapse resulting in subsequent emergency reoperation and open cardiac massage after coronary artery bypass surgery is fatal in almost half of the cases $(46 \%)$.

2. Techincal graft complication is a major (36\%) underlying cause for postoperative hemodynamic collapse following coronary artery bypass surgery.

3. Post-mortem angiography improves the accuracy of autopsy diagnostics of graft complications in cases with fatal outcome following coronary artery bypass surgery. 
4. Cause of death can be revealed in every case after fatal outcome following coronary artery bypass surgery.

5. Medico-legal autopsy by an unbiassed professional provides neutral investigation and results in complete report of the death.

Acknowledgments The work was supported by research grants from the Helsinki University Hospital Special Funds and from the Paavo Ilmari Ahvenainen Foundation.

Conflict of interest The authors declare that they have no conflict of interest.

Open Access This article is distributed under the terms of the Creative Commons Attribution Noncommercial License which permits any noncommercial use, distribution, and reproduction in any medium, provided the original author(s) and source are credited.

\section{References}

1. Puskas JD, Edwards FH, Pappas PA, O'Brien S, Peterson ED, Kilgo P, Ferguson TB Jr. Off-pump techniques benefit men and women and narrow the disparity in mortality after coronary bypass grafting. Ann Thorac Surg. 2007;84:1447-54.

2. Brown PP, Kugelmass AD, Cohen DJ, Reynolds MR, Culler SD, Dee AD, Simon AW. The frequency and cost of complications associated with coronary artery bypass grafting surgery: results from the United States Medicare program. Ann Thorac Surg. 2008;85:1980-6.

3. Whittle J, Conigliaro J, Good CB, Kelley ME, Skanderson M. Understanding of the benefits of coronary revascularization procedures among patients who are offered such procedures. Am Heart J. 2007;154:662-8.

4. Apolito RA, Greenberg MA, Menegus MA, Lowe AM, Sleeper LA, Goldberger MH, Remick J, Radford MJ, Hochman JS. Impact of the New York State Cardiac Surgery and Percutaneous Coronary intervention reporting system on the management of patients with acute myocardial infarction complicated by cardiogenic shock. Am Heart J. 2008;155:267-73.

5. Li Z, Carlisle DM, Marcin JP, Castellanos LR, Romano PS, Young JN, Amsterdam EA. Impact of public reporting on access to coronary artery bypass surgery: the California outcomes reporting program. Ann Thorac Surg. 2010;89:1131-8.
6. Weman SM, Salminen US, Penttilä A, Karhunen PJ. Postmortem cast angiography in the diagnostics of graft complications in patients with fatal outcome following coronary artery bypass grafting (CABG). Int J Legal Med. 1999;112:107-14.

7. Goodwin AT, Goddard M, Taylor GJ, Ritchie AJ. Clinical versus actual outcome in cardiac surgery: a post-mortem study. Eur $\mathbf{J}$ Cardiothorac Surg. 2000;17:747-51.

8. Anthi A, Tzelepis GE, Alivizatos P, Michalis A, Palatianos GM, Geroulanos S. Unexpected cardiac arrest after cardiac surgery: Incidence, predisposing causes and outcome of open chest cardiopulmonary resuscitation. Chest. 1998;113:15-9.

9. El-Banayosy A, Brehm C, Kizner L, Hartmann D, Kortke H, Korner MM, Minami K, Reichelt W, Korfer R. Cardiopulmonary resuscitation after cardiac surgery: a two-year study. J Cardiothorac Vasc Anesth. 1998;12:390-2.

10. Fairman RM, Edmunds LH Jr. Emergency thoracotomy in the surgical intensive care unit after open cardiac operation. Ann Thorac Surg. 1981;32:386-91.

11. McKowen RL, Magovern GJ, Liebler GA, Park SB, Burkholder JA, Maher TD. Infectious complications and cost-effectiveness of open resuscitation in the surgical intensive care unit after cardiac surgery. Ann Thorac Surg. 1985;40:388-92.

12. Raman J, Saldanha RF, Branch JM, Esmore DS, Spratt PM, Farnsworth AE, Harrison GA, Chang VP, Shanahan MX. Open cardiac compression in the postoperative cardiac intensive care unit. Anaesth Intensive Care. 1989;17:129-35.

13. Kaiser GC, Naunheim KS, Fiore AC, Harris HH, McBride LR, Pennington DG, Barner HB, Willman VL. Reoperation in the intensive care unit. Ann Thorac Surg. 1990;49:903-8.

14. Lee AHS, Borek BT, Gallagher PJ, Saunders R, Lamb RK, Livesey SA, Tsang VT, Monro JL. Prospective study of the value of necropsy examination in early death after cardiac surgery. Heart. 1997;78:34-8.

15. Zehr KJ, Liddicoat JR, Salazar JD, Gillinov AM, Hruban RH, Hutchins GM, Cameron DE. The autopsy: still important in cardiac surgery. Ann Thorac Surg. 1997;64:380-3.

16. Saimanen E, Jarvinen A, Penttilä A. Cerebral cast angiography as an aid to medicolegal autopsies in cases of death after adult cardiac surgery. Int J Legal Med. 2001;114:163-8.

17. Karhunen PJ, Männikkö A, Penttilä A, Liesto K. Diagnostic angiography in postoperative autopsies. Am J Forensic Pathol. 1989;10:303-9.

18. Barendregt WB, de Boer HH, Kubat K. Autopsy analysis in surgical patients: a basis for clinical audit. Brit J Surg. 1992;79: 1297-9. 